\title{
Characteristics of Creeping Impulse Streamers over the Surface of Oil-Immersed PE Wire
}

\author{
Member \\ Ryoichi Hanaoka \\ (Kanazawa Institute of Technology) \\ Member \\ Toshiyuki Nishi \\ Student member \\ (Toyama National College of Technology) \\ (Kanazawa Institute of Technology)
}

Creeping impulse discharges occurring at the insulating systems of electric power equipment are significantly affected by the presence of a surrounding grounded metal case. Using a standard lightning impulse voltage, the characteristics of creeping streamers were studied over the surface of an oil-immersed polyethylene (PE) insulated wire with a grounded side electrode. The discharge characteristics (discharge aspect, streamer extension length, streamer current and charge, etc.) were measured as a function of the distance between the PE wire and the grounded side electrode. Streamer polarity and the position of the side electrode significantly affected both streamer generation and propagation. The creepage characteristics were also examined using two methods of voltage application. Differences in the test results of each method were attributed to the position of the side electrode. The potential distribution inside the streamer channel and the streamer propagation velocity were measured by means of a potential probe. Streamer velocity was found to be constant and the streamer channel was not equipotential.

Key words: Transformer oil, Lightning impulse voltage, PE insulated wire, Creepage discharge, Streamer potential

\section{Introduction}

The creepage discharge occurring in electric power equipments due to an overvoltage condition (such as lightning surge) is one of most important problems in efforts to design reliable insulation for large-capacity and miniaturized apparatus. Electrical failures within the internal insulating systems of electric power equipment can be broadly divided into two categories; punch-through breakdown of the solid insulator and creeping discharge over the insulator surface. The process of electrical breakdown has been studied extensively for various insulating materials by many researchers and its mechanism is well understood. Many studies on creeping discharge in gases such as air and SF6 have used a Lichtenberg figure, a high-speed camera, etc., to record streamer propagation $[1,2]$. Several researchers have also studied the electrical characteristics of creeping streamers along the surface of solid insulators in insulating oil [3-7]. These studies show that streamer development is unaffected by the oil, however, the surface conditions of the solid-liquid interface complicate the discharge phenomena. The properties of creeping discharge within oil-filled equipment remain largely unknown.
Many types of a practical electric power equipment such as elephant transformer and oil-filled bushing include the joints of high-voltage cable termination (cable head and elephant head) and the cable supporting metals (dipost and tripost, guard band and its terminal, semiconducting shield and grounded metal case). These equipments are exposed to danger of a creepage failure which can occur at the metal portions within the insulating systems by the overvoltage from a lightning surge.

This paper describes the properties of streamers traveling over the surface of oil-immersed polyethylene (PE) insulated wire under a standard lightning impulse voltage application. The study was performed on the assumption that when a lightning surge invaded the cable of oil-filled equipments, creepage discharges happened at supporting metal fittings of insulating systems. A simple model that the PE insulated wire in transformer oil was supported by the copper binding wire was used in this experiment. The effect of a grounded side electrode upon discharge characteristics was studied by applying a lightning impulse to either the central line of the sample test wire or the binding wire. In addition, the potential drop inside the streamer channel and the streamer propagation velocity were measured using a potential probe. 


\section{Experimental Setup and Procedure}

The internal insulating systems of oil-filled equipments are usually confined within a grounded metal case. In several equipments, the distances between the insulating system and the ground were designed over the range of $50 \sim$ $300 \mathrm{~mm}$ (for example, $50 \sim 78 \mathrm{~mm}$ and $205 \sim 290 \mathrm{~mm}$ for 20kVA and 5000kVA transformers (Meidensha Co., Ltd.), and $136 \mathrm{~mm}$ and $189 \mathrm{~mm}$ for $77 \mathrm{kV}$ and $154 \mathrm{kV}$ oil-filled bushings (Fuji Electric Co., Ltd.), respectively). A copper plate $(150 \mathrm{~mm}$ in width and $300 \mathrm{~mm}$ in length) used in this experiment functioned as the grounded metal case (the side electrode), and was separated from the center of the test wire by distance $h$. The maximum distance of $h$ was $500 \mathrm{~mm}$.

The experimental setup is shown schematically in Fig. 1(a). The PE insulated wire, which is described in Table 1, was used as the test wire. The wire was immersed in commercial transformer oil (JIS C-2320) which was filtered through a $8 \mu \mathrm{m}$ sintered glass filter and supported by the copper binding wire $(1.6 \mathrm{~mm}$ dia.) fastened to the surface of the test wire. In order to observe the creeping discharges which propagate to one direction, one end of the binding wire had a sharp edge with a radius of curvature of about $150 \mu \mathrm{m}$ and $70 \mathrm{~mm}$ in length. This free end of the binding wire was lightly touching the insulated surface of the test wire. In this geometry, creeping streamers always originated from the free end and were not affected by the ringed portion of the binding wire when the grounded copper plate was positioned facing the free end.

The impulse voltage generator (I.G.) generated an impulse voltage of $1.2 / 50 \mu \mathrm{s}$ with a maximum peak value of $\pm 85 \mathrm{kV}$ and was applied to the central line of the test wire or the binding wire. When the voltage was applied to the central line, the binding wire was grounded through the circuit with a light-emitting diode (LED), as shown by the broken lines in Fig. 1(a). If a positive voltage was applied to the central line, the polarity of the streamer became negative. Conversely, the streamer became positive when a negative voltage was applied. When the voltage was applied to the binding wire, the central line of the test wire was grounded and the LED circuit was connected to the high voltage side, as shown by the dotted lines in Fig.1(a). In this case, the polarity of the streamers was the same as the applied voltage. Streamer extension length and discharge aspect were measured using a camera equipped with an image intensifier. The discharge current flowing through the binding wire and the emission of light were detected by means of an electro-optic coupling with LED and a photodiode, and the electric charge was measured using an inte-

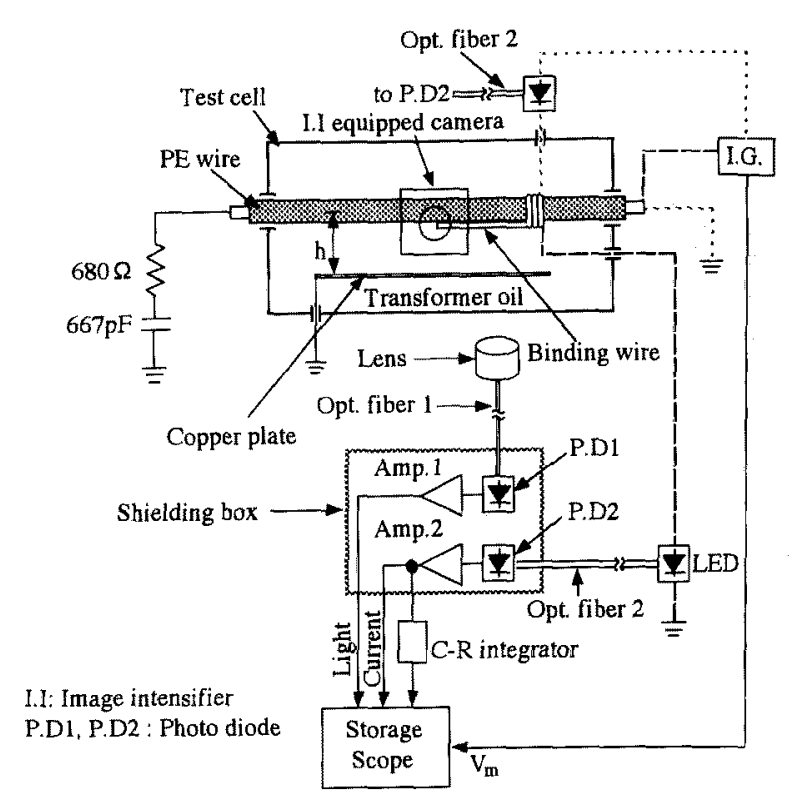

(a) Diagram of experimental setup

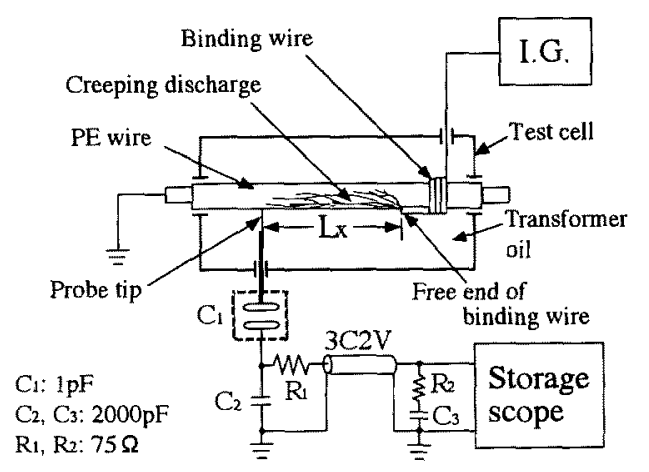

(b) Diagram of potential probe

Fig.1. Schematic diagram of experimental setup.

Table 1. Description of insulated wire used in experiments.

\begin{tabular}{l|c|c|c|c|c|c}
\hline \multirow{2}{*}{$\begin{array}{l}\text { Finished } \\
\begin{array}{l}\text { outside } \\
\text { dia. } \\
(\mathrm{mm})\end{array}\end{array}$} & $\begin{array}{l}\text { Stated } \\
\text { cross } \\
\text { section } \\
\left(\mathrm{mm}^{2}\right)\end{array}$ & $\begin{array}{l}\text { No. \& } \\
\text { dia. of } \\
\text { wire } \\
(\mathrm{mm})\end{array}$ & $\begin{array}{l}\text { Outside } \\
\text { dia. }\end{array}$ & $\begin{array}{l}\text { Thickness } \\
\text { of ins. } \\
\text { material } \\
(\mathrm{mm})\end{array}$ & $\begin{array}{l}\text { Main } \\
\text { material }\end{array}$ & $\begin{array}{l}\text { Relative } \\
\text { permit- } \\
\text { tivity }\end{array}$ \\
\hline 10.0 & 22.0 & $7 / 2.0$ & 6.0 & 2.0 & $\begin{array}{l}\text { Poly- } \\
\text { ethylene }\end{array}$ & 2.3 \\
\hline
\end{tabular}

grating circuit. The surface condition of the test wire insulator was maintained by grounding the wire after each voltage application and the voltage was applied at intervals of more than 10 minutes.

A potential probe as shown in Fig.1(b) was used to de- 
termine the streamer velocity and the potential drop inside the streamer channel. This probe was similar in principle to the probe used in air by Nishi et al. [8]. The tip of the probe was made of $0.5 \mathrm{~mm}$ dia. copper wire etched to a tip radius of $50 \mu \mathrm{m}$, and positioned perpendicular to the surface of the test wire insulator at distance $\mathrm{Lx}$ from the free end of the binding wire. Capacitor $\mathrm{C}_{1}$ consisted of two parallel copper disks having a Rogowsky profile of $50 \mathrm{~mm}$ in diameter and separated $46 \mathrm{~mm}$ apart in transformer oil with a capacitance of about $1 \mathrm{pF}$. Capacitor $\mathrm{C}_{2}$ was a mica type of $2000 \mathrm{pF}$. The potential drop inside the streamer channel could be accurately measured since after the probe was positioned, the input impedance of the probe was fairly high relative to the internal impedance of the streamer.

\section{Experimental Results and Discussions}

\subsection{Aspects of Streamer Propagation}

Typical photographs of creeping discharges are shown in Fig. 2 for both positive and negative streamer polarities when voltage was applied to the central line of the test wire (Fig.2(A)) and to the binding wire (Fig.2(B)). In Fig. 2(A) and (B), photographs (a) were obtained at $h=500 \mathrm{~mm}$, (b) at $\mathrm{h}=40 \mathrm{~mm}$. At $\mathrm{h}=500 \mathrm{~mm}$, positive and negative streamer propagation did not differ significantly whether the impulse voltages were applied to the central line or to the binding wire. Photographs at $h=40 \mathrm{~mm}$ clearly indicated the effect of $h$ on the propagation of streamers for both polarities. When voltage was applied to the central line (Fig.2(A)), a reduction of $h$ restrained the propagation of streamers for both polarities. Compared with (a) and (b) in Fig.2(A), the streamer extension lengths at $h=40 \mathrm{~mm}$ were shorter than those at $\mathrm{h}=500 \mathrm{~mm}$. Conversely, when the voltage was applied to the binding wire (Fig.2(B)), the propagation of streamers was facilitated by a reduction of $h$. Compared with (a) and (b) in Fig.2(B), the streamer lengths at $h=$ $40 \mathrm{~mm}$ were longer than those at $\mathrm{h}=500 \mathrm{~mm}$. From Fig. 2 (B)-(b), we can also see the propagation of streamers through the oil to the side electrode; streamers propagating from the free end of the binding wire to the under direction. These are due to the electric field enhancement in the liquid between the binding wire and the side electrode which was caused by the reduction of $h$.

Figure 2 also illustrates the difference in discharge form between positive and negative streamers. Positive streamers exhibited a distinctive tree-like shape compared to the negative streamers, which had a fuzzy aspect and more bush-like appearance. These characteristic forms were similar to results obtained using point-plane or point-

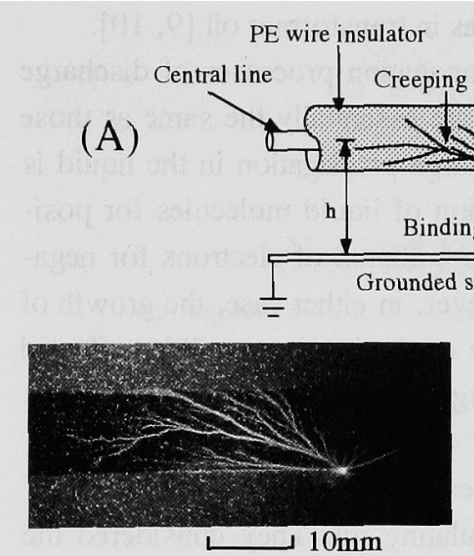

(a) $\mathrm{h}=500 \mathrm{~mm}, \mathrm{~V}_{\mathrm{m}}=-73.8 \mathrm{kV}$

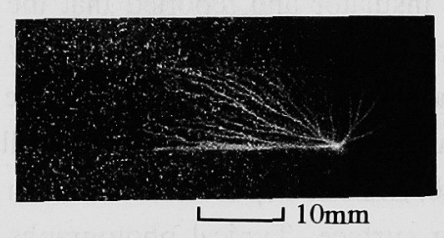

(b) $\mathrm{h}=40 \mathrm{~mm}, \mathrm{~V}_{\mathrm{m}}=-72.4 \mathrm{kV}$

Positive streamers (a) $\mathrm{h}=500 \mathrm{~mm}, \mathrm{Vm}=74.1 \mathrm{kV}$

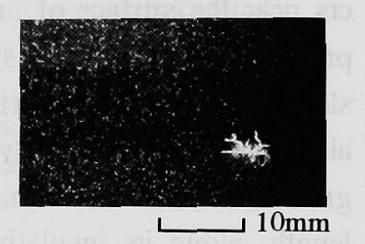

(b) $\mathrm{h}=40 \mathrm{~mm}, V_{\mathrm{m}}=74.2 \mathrm{kV}$

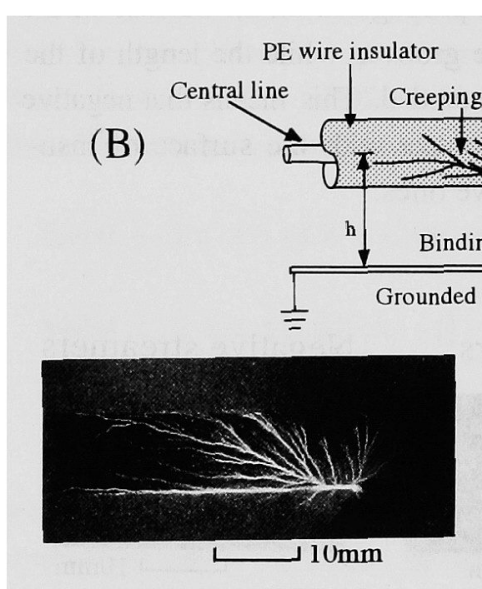

(a) $\mathrm{h}=500 \mathrm{~mm}, \mathrm{~V}_{\mathrm{m}}=74.4 \mathrm{kV}$

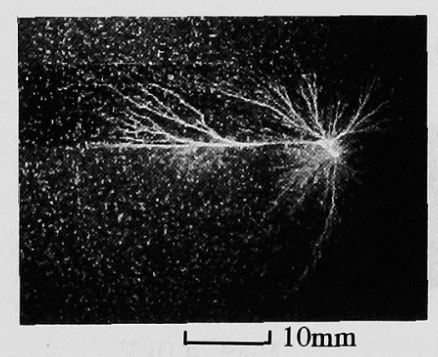

(b) $\mathrm{h}=40 \mathrm{~mm}, \mathrm{~V}_{\mathrm{m}}=75.2 \mathrm{kV}$

Positive streamers

\section{Negative streamers}

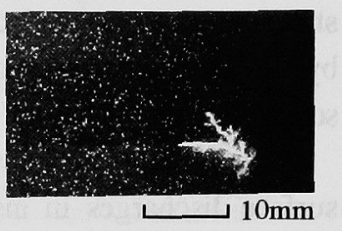

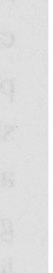

\section{s}

. 
sphere electrode geometries in transformer oil $[9,10]$.

It is thought that the propagation processes of discharge in a solid-liquid interface are essentially the same as those in a bulk liquid; the discharge propagation in the liquid is based on the field ionization of liquid molecules for positive streamers, and on the collision of electrons for negative streamers [11]. However, in either case, the growth of streamers near the surface of the insulator will be affected by the force on the charges (electrons and ions) at the solid-liquid interface.

Kishida et al. [12] investigated the effect of a slot on surface discharges in insulating oil. They considered the forces on electrons that participate in the growth of streamers near the surface of an insulator and reported that the propagation of negative streamers was greatly affected by slots on the insulator surface. The same conclusions were also obtained in this study using a sample wire with a small groove, $0.4 \mathrm{~mm}$ in width, $0.1 \mathrm{~mm}$ in depth and $100 \mathrm{~mm}$ in length, along its insulating surface. Typical photographs are shown in Fig. 3 for both streamer polarities. Figure 4 shows the relationship between the streamer extension length $\mathrm{Lm}$ and the peak value of applied voltage $\mathrm{V}_{\mathrm{m}}$. The positive streamers always propagated on the surface of the wire independently of the groove, while the length of the negative streamers was extended. This means that negative streamers propagate in contact with the surface of insulator, in contrast to positive ones.

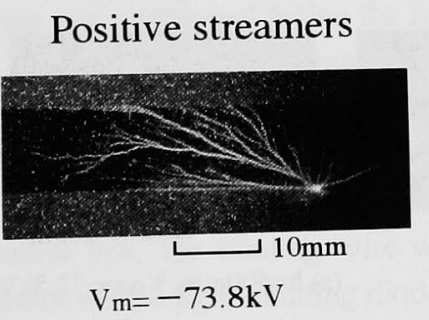

Negative streamers

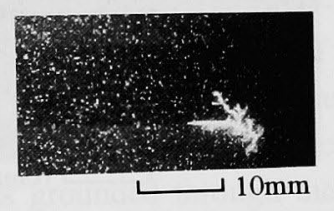

$\mathrm{Vm}=74.1 \mathrm{kV}$

(a) without groove
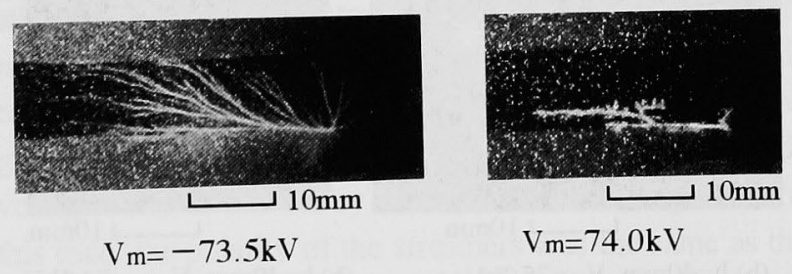

(b) with groove

Fig.3. Typical photographs of creeping streamers with and without small groove on test wire surface. Voltage applied to central line of test wire. $h=500 \mathrm{~mm}$.

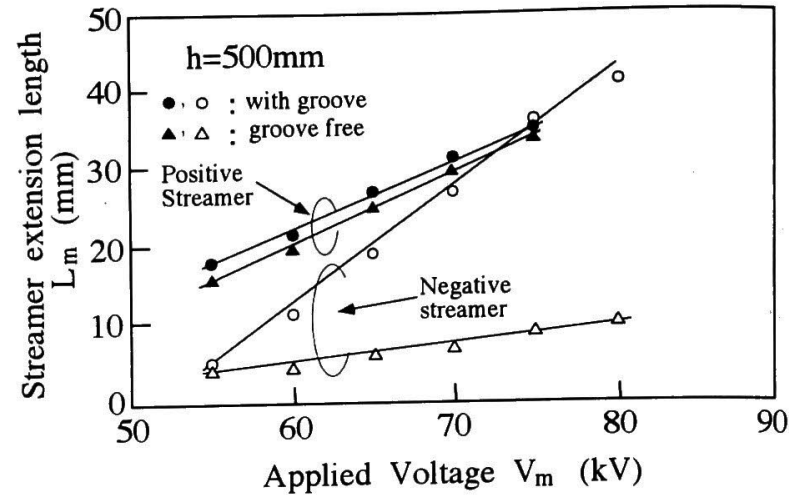

Fig.4. Effect of small groove on relationships between $\mathrm{Lm}$ and $\mathrm{V}_{\mathrm{m}}$. Voltage applied to central line of test wire.

\subsection{Influence of Grounded Side Electrode on Streamer Propagation}

The behavior of creeping discharges can be changed by altering the distance $h$. The effect of $h$ upon the propagation of creeping streamers was investigated using a sample wire with an ungrooved insulator surface. Figure 5(a) and (b) show the effect of $h$ on the relationships between $\mathrm{Lm}$ and $\mathrm{V}_{\mathrm{m}}$ obtained from two methods of voltage application and for both streamer polarities. The discharge inception voltage $V_{i}$ is also shown in Fig. 5(a) and (b) for each h. Vi was defined as the voltage that started the first discharge obtained using the image intensifier at the free end of the binding wire. The streamer lengths for $\mathrm{V}_{i}$ ranged from 10 15mm for positive streamers and $2 \sim 4 \mathrm{~mm}$ for negative streamers. The data indicated a linear relation between $\mathrm{Lm}_{m}$ and $\mathrm{V}_{\mathrm{m}}$ for both polarities. Each symbol in the graphs represents ten fixed voltage measurements with a standard deviation of less than $\pm 10 \%$. These linear characteristics were already observed by Okubo et al. [13] and Atten et al. [6, 7].

On the other hand, when the impulse voltage was applied to the central line of the test wire, Lm decreased with decreasing $\mathrm{h}$ under a fixed voltage (solid lines in Fig.5). Conversely, $\mathrm{Lm}$ increased with decreasing $\mathrm{h}$ when the voltage was applied to the binding wire (broken lines in Fig.5). It is considered that these properties are related to the electric field strength near the solid-liquid interface which is significantly affected by $h$.

In this study, two insulating media have almost the same values of the relative permittivity $\varepsilon$ s, i.e. $\varepsilon_{\mathrm{s}}=2.2$ for transformer oil and $\varepsilon_{\mathrm{s}}=2.3$ for PE. Therefore, electric field geometry at the solid-liquid interface is regarded as a continuity. In this case, the experimental configuration is 

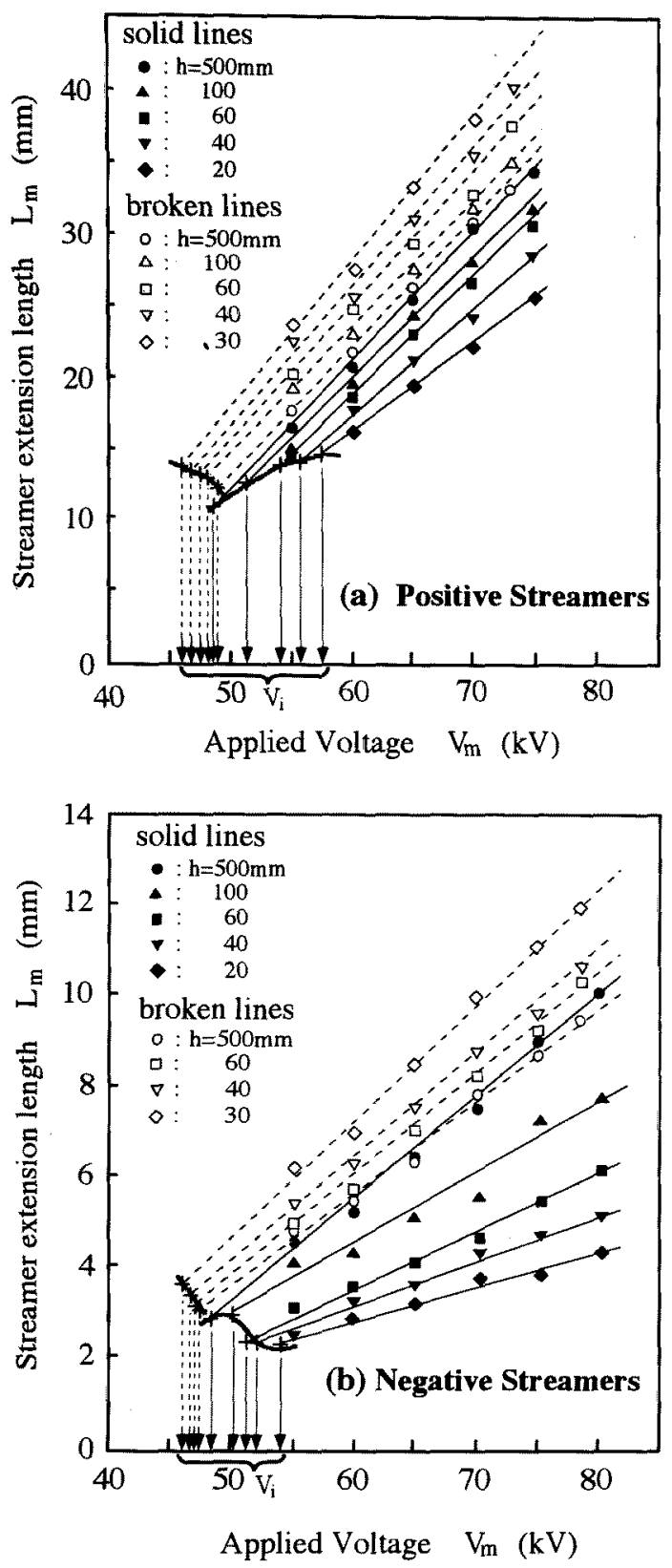

Fig.5. Relationship between $\mathrm{h}, \mathrm{Lm}, \mathrm{Vm}$ and Vi. Surface of test wire is groove-free. Solid symbols and solid lines: voltage was applied to central line of test wire. Hollow symbols and broken lines: voltage was applied to binding wire.

simulated by the model as shown in Fig.6(a), where $\varepsilon$ denotes the permittivity of oil. The electric field lines differ between two methods of voltage application as shown in Fig.6(b) and (c), but in either case, a strong non-uniform field is formed at the free end of the binding wire. The streamer will start from the free end when the electric field strength exceeded the breakdown strength of the oil (about $120 \mathrm{kV} / \mathrm{cm})$.

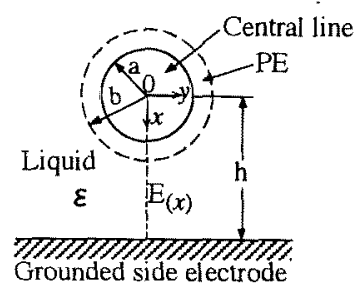

(a) Model of experimental configuration

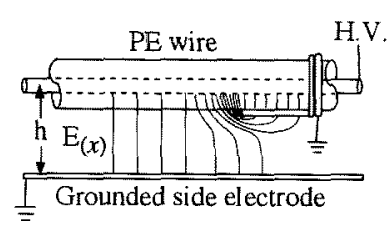

(b) Electric field lines. (Voltage is applied to central line.)

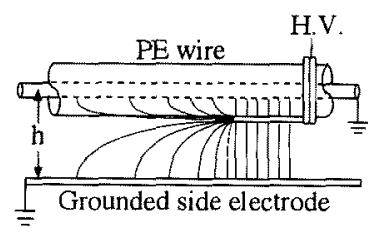

(c) Electric field lines. (Voltage is applied to binding wire.)
Fig.6. Model of experimental configuration and schematic diagram of electric field lines near free end of binding wire.

When voltage is applied to the central line (Fig.6(b)), streamers must progress cross the electric field $\mathrm{E}(x)$ which is perpendicular to the wire insulator surface. The electric field $\mathrm{E}(x)$ and potential $\mathrm{V}(x)$ along the $x$ axis in media between the central line and the side electrode are represented from Fig.6(a) as follows (except near the free end).

$$
\begin{aligned}
& \mathrm{E}(x)=(\lambda / 2 \pi \varepsilon)\{1 / x+1 /(2 \mathrm{~h}-x)\} \\
& \mathrm{V}(x)=(\lambda / 2 \pi \varepsilon) \ln |(2 \mathrm{~h} / x)-1| \\
& \lambda=2 \pi \varepsilon \mathrm{V} / \ln |(2 \mathrm{~h} / \mathrm{a})-1|
\end{aligned}
$$

where $\mathrm{V}$ denotes the applied voltage, a the radius of the central line and $\mathbf{b}$ the radius of the insulated sample wire. The electric field strength $\mathrm{E}(\mathrm{b})$ and potential $\mathrm{V}(\mathrm{b})$ at the test wire surface can be calculated by putting $x=b$ in Eqs. (1) and (2). $E(b)$ increases exponentially with decreasing $h$ (e.g., in $\mathrm{V}=70 \mathrm{kV}, \mathrm{E}(\mathrm{b})=24 \mathrm{kV} / \mathrm{cm}$ for $\mathrm{h}=500 \mathrm{~mm}$ and $\mathrm{E}(\mathrm{b})$ $=52 \mathrm{kV} / \mathrm{cm}$ for $\mathrm{h}=30 \mathrm{~mm}$ ). Therefore, the Coulomb force $\mathrm{Fe}$ on electrons which participate in the growth of streamers will also increase (e.g., in $\mathrm{V}=70 \mathrm{kV}, \mathrm{Fe}$ in $\mathrm{h}=30 \mathrm{~mm}$ becomes 2.2 times larger than $\mathrm{h}=500 \mathrm{~mm}$ ). It is considered that the force $\mathrm{Fe}$ retards streamer propagation since $\mathrm{Fe}_{\mathrm{e}}$ acts perpendicularly to the streamer progression direction. As a result, the reduction of $h$ leads to the decrease of $\mathrm{Lm}$ under a fixed voltage. The potential difference $V_{a b}$ between the central line and the wire insulator is also estimated from Eq. (2) as $V_{a b}=V_{(a)}-V_{(b)}$; for example, in $V=70 k V, V_{a b}$ in $\mathrm{h}=30 \mathrm{~mm}$ is 2.1 times larger than $\mathrm{h}=500 \mathrm{~mm}$. This will result in a decrease of the insulator breakdown voltage $V_{B}$. 

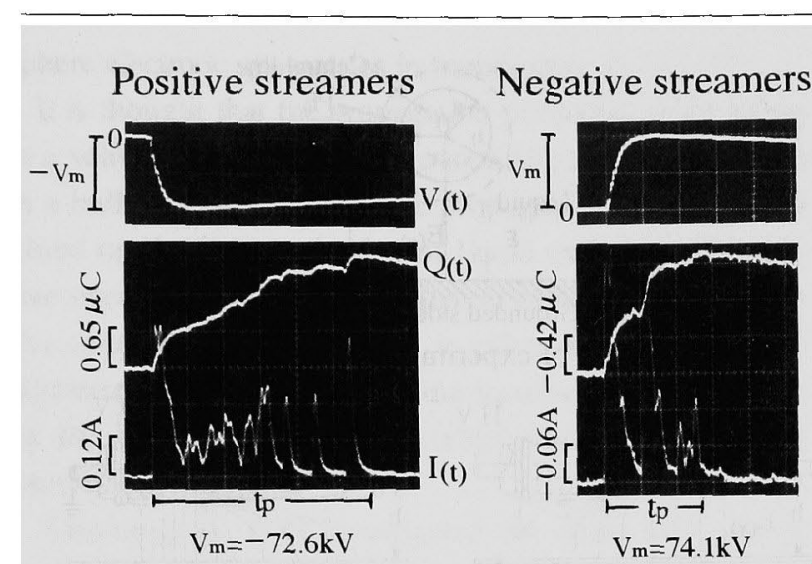

(a) $\mathrm{h}=500 \mathrm{~mm}$

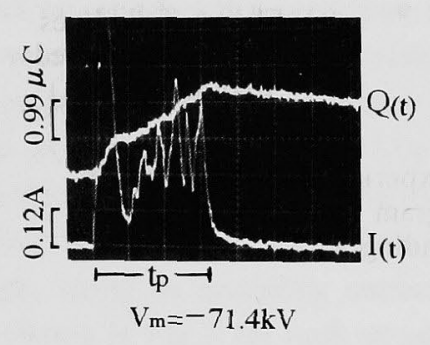

(b) $\mathrm{h}=40 \mathrm{~mm}$

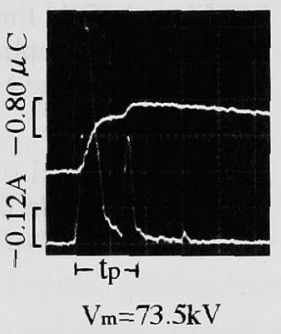

(A)

\section{Positive streamers}

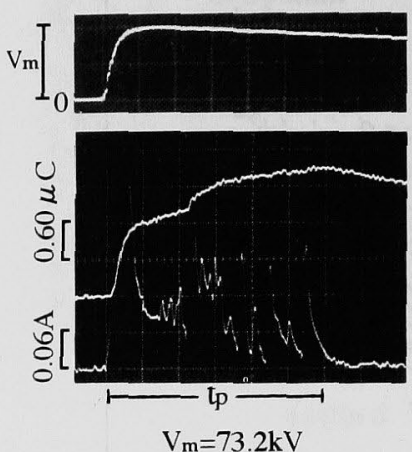

(a) $\mathrm{h}=500 \mathrm{~mm}$

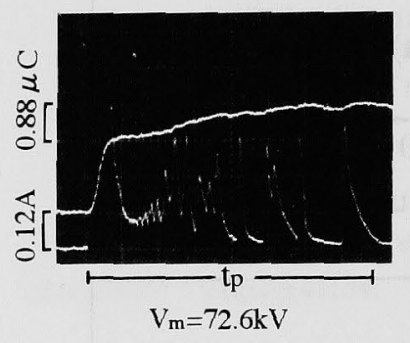

(b) $\mathrm{h}=40 \mathrm{~mm}$
Negative streamers
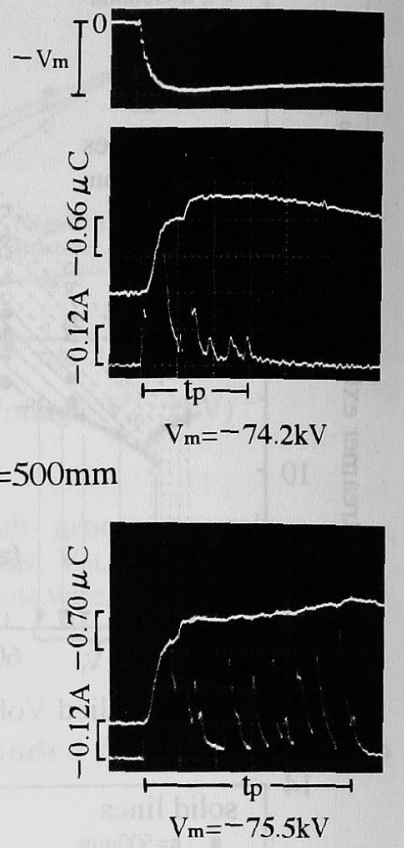

(B)

Fig.7. Typical variations in time of discharge current $I(t)$ and electric charge $Q(t)$. (time scale: $2 \mu \mathrm{s}$ /div.). $V(t)$ is applied voltage. (A): voltage applied on central line of test wire, (B): voltage applied on binding wire.

In this experiment, frequent punch-through breakdown of the test wire insulator was always caused by positive discharges, with punctures occurring just below the free end of the binding wire. When $h$ was changed from 500 to 20 $\mathrm{mm}, \mathrm{VB}$ dropped from 85 to $75 \mathrm{kV}$.

When voltage is applied to the binding wire (Fig.6(c)), the electric field that contributes to the propagation of streamers is formed by the streamer itself, since the central line and the side electrode are grounded. Therefore, small components of the electric field perpendicular to the wire insulator are present where the streamers propagate. With the reduction of $h$, a higher electric field is formed in liquid between the streamer and the side electrode. Then, the streamer will be compeled to propagate towards the side electrode. The streamer progression is thus facilitated along the surface of the wire insulator. This experiment was conducted without wire insulator punctures. However, when $\mathrm{h}<20 \mathrm{~mm}$, the breakdown in liquid between the free end of the binding wire and the side electrode occurred.

\subsection{Electro-Optic Measurements of Creeping Discharge}

Typical variations in the discharge current $I(t)$ are shown in Fig. 7(A) and (B) for the two methods of voltage application. In all the current waveforms, the first large current pulse, which occurs just after voltage application, appears to be a combination of injection current and charging current. After this large pulse, intermittent current pulses were visible in the wave tail of the applied voltage. The amplitude of the individual current pulses increased with decreasing $\mathrm{h}$ for both streamer polarities. When the voltage was applied to the central line (Fig.7(A)-(a),(b)), the pulse sustaining time $t_{p}$ decreased with decreasing $h$. Converse$l y, t_{p}$ increased with decreasing $h$ when voltage was applied to the binding wire (Fig.7(B)-(a),(b)). These tp-values appeared to be dependent on $\mathrm{Lm}$. Therefore, assuming that the streamer grows at a constant velocity, the mean velocity $\overline{\mathrm{U}}_{\mathrm{s}}$ can be estimated to a first approximation (from Lm-values in Fig.5 and tp-values in Fig.7) as follows:

$$
\overline{\mathrm{U}}_{\mathrm{s}}=\mathrm{Lm} / \mathrm{t}_{\mathrm{p}}
$$

Current and light pulses appeared to coincide for both streamer polarities. It is most likely that these pulses correspond to the individual branches of the streamers. These results are similar to those obtained for streamers in liquid alone $[14,15]$. 
The amplitude of current pulses and $t p$ are also relative to the total charge, which is determined by $Q=\int \mathrm{I}(\mathrm{t}) \mathrm{dt}$, $(\mathrm{t}$ $=$ time). The variations in the charge $Q(t)$ were obtained using the integrating circuit. Typical oscillograms of $Q(t)$ are shown in Fig.7, along with the associated current waveforms. The charge due to the intermittent current pulse is added to the charge from the first large current pulse. The influence of $h$ on the relationship between $Q$ and $V_{m}$ is shown in Fig.8(a) and (b). In case of the voltage application on the binding wire (broken lines), the increase
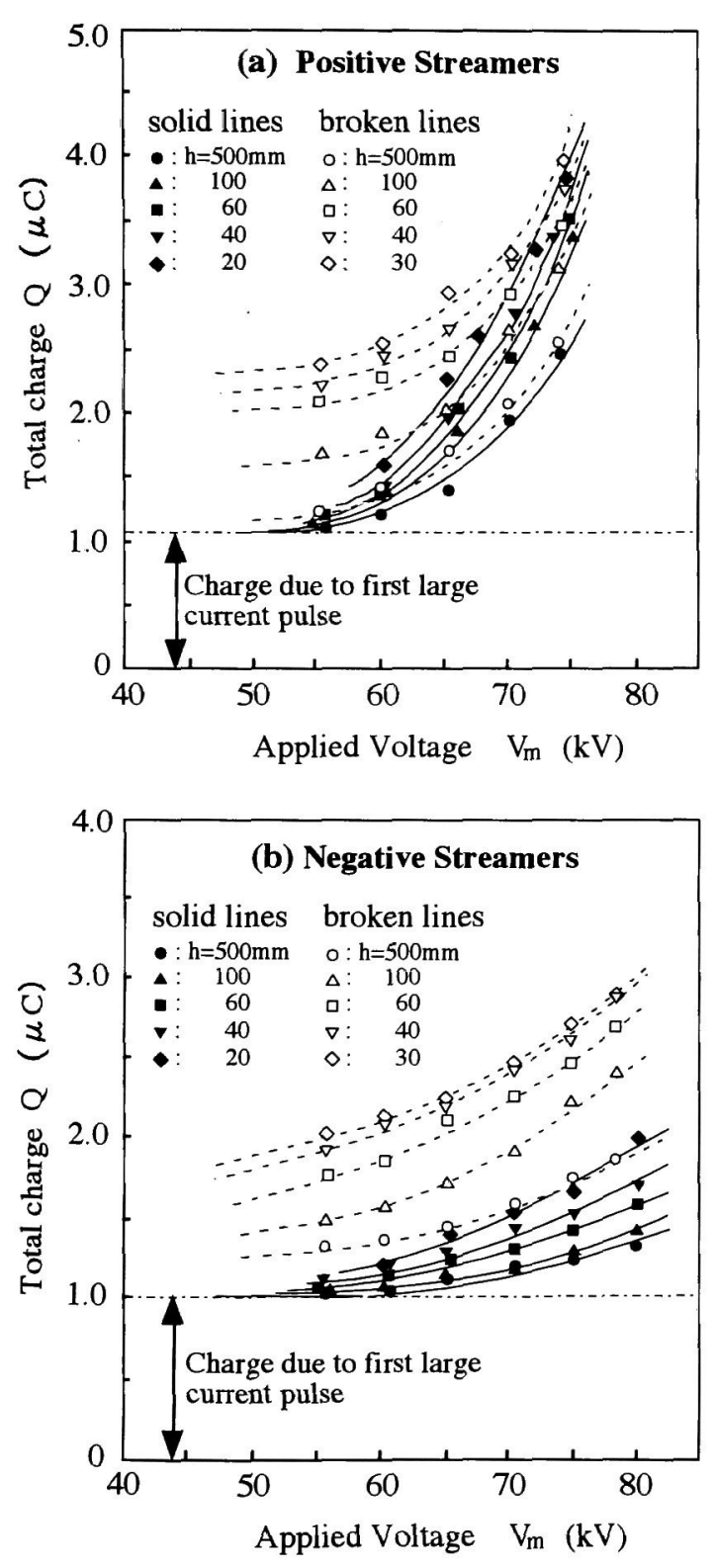

Fig.8. Relationship between $h, Q$ and $V m$. Surface of test wire is groove-free. Solid symbols and solid lines: voltage applied to central line of test wire. Hollow symbols and broken lines: voltage applied to binding wire. in $\mathrm{Q}$ is due to both a larger charging current and the increase in $t_{p}$, resulting from the reduction of $h$. The data in Fig. 8 denotes that $Q$ rises at different rates according to the increments of $V_{m}$, since $Q$ varies nonlinearly with $V_{m}$. Concerning a nonlinear variation of $Q$ vs. $V_{m}$, Atten and Saker $[6,7]$, after studying the electrical properties of the creeping streamers in transformer oil, have showed that the current associated with the creepage discharges was of capacitive nature, and they reported that the total charge should have a variation in the form of a second-degree polynomial in $\mathrm{V}_{\mathrm{m}}$.

\subsection{Measurements of Streamer Propagation Velocity and Potential Drop Inside the Streamer Channel}

In the measurements of the streamer velocity and the potential drop inside the streamer channel, the voltage was applied to the binding wire and $\mathrm{h}$ was fixed to $500 \mathrm{~mm}$.

When a streamer starting from the free end of the binding wire reaches the probe at position $\mathrm{Lx}$ over time $\mathrm{t}_{\mathrm{x}}$, the probe potential increases rapidly from roughly zero to the streamer potential Vs. A typical output from the probe is shown in Fig.9. The potential drop $\mathrm{Vd}_{\mathrm{d}}$ of the streamer

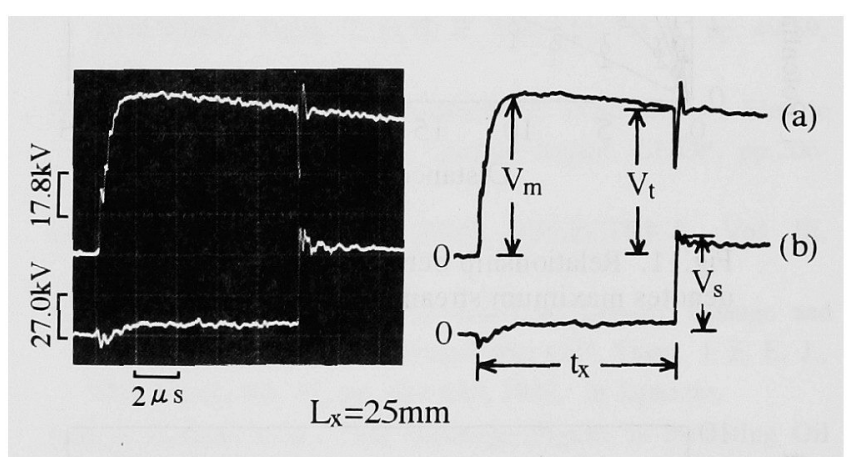

Fig.9. Typical variation of probe potential. (a): applied voltage, (b): probe potential.

channel is obtained from the difference between $V_{s}$ and the applied voltage $V_{t}$ at time $t_{x}\left(V_{d}=V_{t}-V_{s}\right)$. The streamer propagation velocity $U_{s}$ is given by

$$
\mathrm{Us}=\mathrm{Lx} / \mathrm{tx} \text {. }
$$

Figure 10 shows the relationship between tx and Lx. Time tx increased linearly with Lx, resulting in a constant propagation velocity. The velocities were about $2.4 \mathrm{~km} / \mathrm{s}$ for positive streamers and about $1.8 \mathrm{~km} / \mathrm{s}$ for negative streamers, similar to those obtained by Okubo et al. [13]. The 


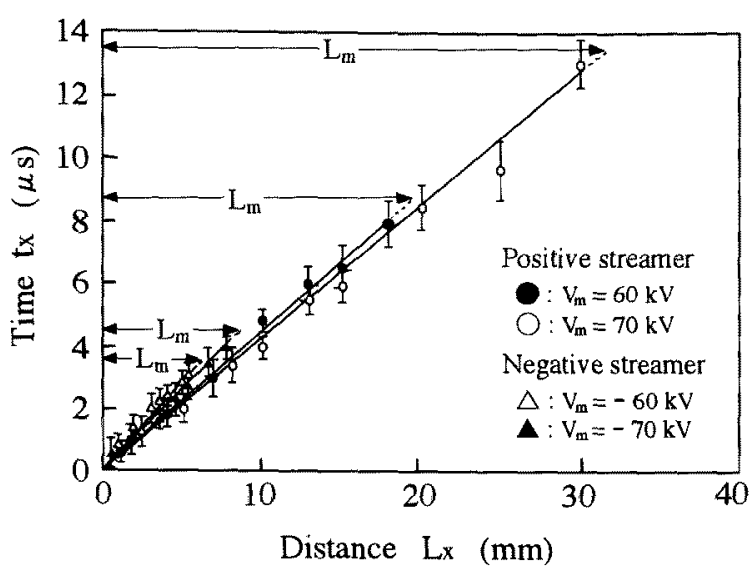

Fig.10. Relationship between $\mathrm{tx}$ and $\mathrm{Lx}$. Lm denotes maximum streamer length.

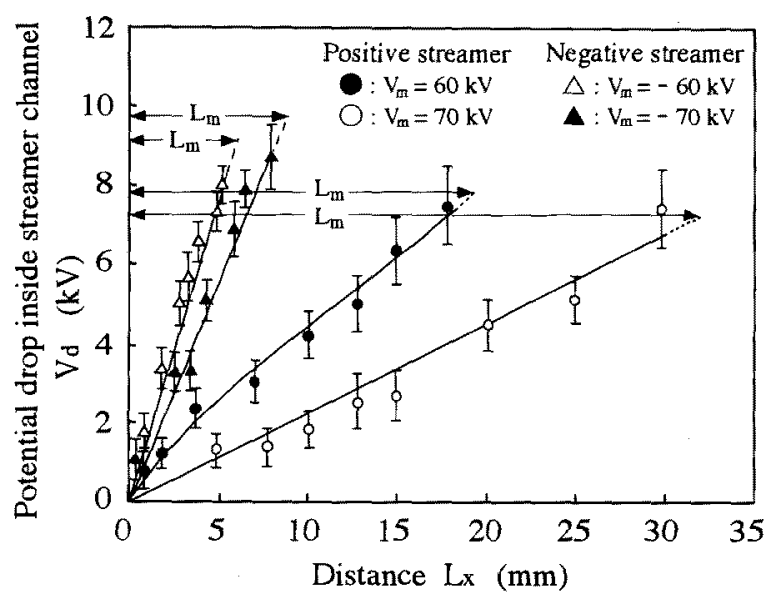

Fig.11. Relationship between $\mathrm{Vd}$ and $\mathrm{Lx}$. Lm denotes maximum streamer length.

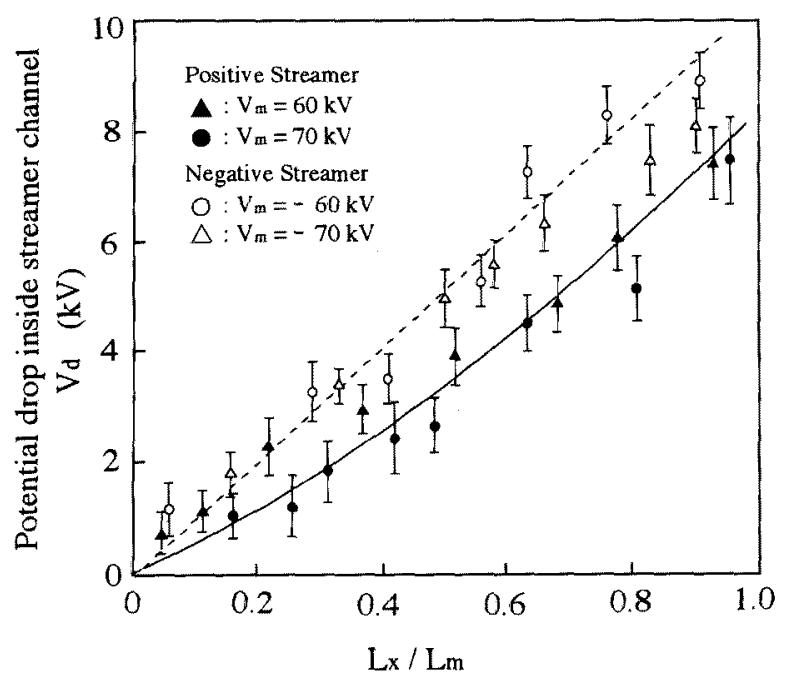

Fig.12. Relationship between $\mathrm{Vd}$ and $\mathrm{Lx} / \mathrm{Lm}$. current flows depending on the streamer length as mentioned above and the streamer grows at a constant velocity. This means that the streamer velocity $U_{s}$ can be regarded as the mean velocity $\bar{U}_{s}$. We confirmed that $U_{s}$ obtained from the probe was much the same as $\overline{\mathrm{U}}_{\mathrm{s}}$ estimated by Eq.(2) under a fixed voltage $\left(V_{m}= \pm 70 \mathrm{kV}\right)$. Faster streamers have been reported in bulk liquid [10]. Figure 11 shows the relationship between $V_{d}$ and $L x$. $V_{d}$ increased approximately linearly with $\mathrm{Lx}$, which corresponded to a constant voltage gradient inside the streamer channel (several $\mathrm{kV}$ / $\mathrm{cm}$ ). In order to clarify the dependence of $V_{m}$ upon $V_{d}$, the potential distribution of Fig.11 was redrawn as a function of $\mathrm{Lx} / \mathrm{Lm}$. $\mathrm{V}_{d}$ appeared to be the same independently of $V_{m}$ for each streamer polarity, as shown in Fig.12. It is most likely that streamer propagation stops when the potential drop inside the channel reaches some fixed value $(9.5 \mathrm{kV}$ for negative streamer and $7.5 \mathrm{kV}$ for positive streamer).

The propagation of creeping streamers is based on an ionization process involved in the pre-breakdown of the liquid near the solid insulator. This process requires ionization in the liquid ahead of the streamer tip and therefore is strongly dependent on the electric field strength. The curves of $\mathrm{V}_{\mathrm{d}}$ shown in Fig.12 suggested the potential drop $V_{F}$ in the final length $L_{m}$ of the streamer. As a result, the potential $V_{s c}$ of the streamer tip against the central line can be estimated from the applied voltage $V_{p}$ at the time tp (Fig.7) and $V_{F}$, i.e. $V_{S C}=V_{P}-V_{F}$. The local electric field strength from $V_{S C}$ at the streamer tip contributes to streamer propagation.

By the way, the propagation process may begin with vaporization of the liquid at the solid-liquid interface and the formation of bubbles at that site on the solid insulator. The energy $\mathrm{H}$ that is required to evaporate a unit volume of the oil under atmospheric pressure is given by

$$
\mathrm{H}=\int_{\mathrm{Ta}}^{\mathrm{Tb}} \rho(\mathrm{T}) \mathrm{C}_{\mathrm{p}}(\mathrm{T}) \mathrm{dT}+\rho\left(\mathrm{T}_{\mathrm{b}}\right) \mathrm{L}_{\mathrm{a}}
$$

where $\mathrm{T}_{\mathrm{a}}$ denotes the temperature of the oil $\left(20^{\circ} \mathrm{C}\right.$ in this study), $\mathrm{T}_{b}$ the boiling point $\left(305^{\circ} \mathrm{C}\right), \rho(\mathrm{T})$ and $\rho\left(\mathrm{T}_{\mathrm{b}}\right)$ the density of the oil at the temperatures $T$ and $T_{b}, C_{p}(T)$ the specific heat at $\mathrm{T}$, and $\mathrm{L}_{\mathrm{a}}$ the latent heat of evaporation $(271.3 \mathrm{~J} / \mathrm{g})$. The energy $\mathrm{W}$ which is transferred to the liquid by the creeping discharge is given by

$$
\mathrm{W}=\mathrm{Q} \cdot \mathrm{V}
$$

where $Q$ denotes the total charge (measured in this study) and $\mathrm{V}$ the applied voltage. If the liquid volume $\nu_{\mathrm{L}}$ in $\mathrm{cm}^{3}$ is evaporated by the energy $\mathrm{W}$, then, $v_{\mathrm{L}}=\mathrm{W} / \mathrm{H}$. Assuming that $\rho(\mathrm{T})$ and $\mathrm{C}_{\mathrm{p}}(\mathrm{T})$ is independent of the temperature (i.e. 
$\rho(\mathrm{T}) \fallingdotseq \rho\left(\mathrm{T}_{\mathrm{b}}\right)=0.898 \mathrm{~g} / \mathrm{cm}^{3}$ and $\mathrm{C}_{\mathrm{p}}(\mathrm{T})=1.9 \mathrm{~J} / \mathrm{g} \cdot \mathrm{deg}$ in transformer oil), $\mathrm{H}=730 \mathrm{~J} / \mathrm{cm}^{3}, \mathrm{~W}=0.072 \sim 0.28 \mathrm{~J}$, and then $v_{\mathrm{L}}$ is about $(1 \sim 4) \times 10^{-4} \mathrm{~cm}^{3}$. The gaseous volume $v_{\mathrm{G}}$ is given by $v_{\mathrm{G}}=\mathrm{K} v_{\mathrm{L}}$, where $\mathrm{K}$ is a coefficient due to the phase change (usually $\mathrm{K}=100 \sim 200$ under atmospheric pressure). The above-mentioned $v_{\mathrm{L}}$ corresponds to the spherical gaseous volume of $2.7 \sim 5.3 \mathrm{~mm}$ in diameter. This result suggests that the low density region of liquid is formed at the site of streamers propagated firstly and this will affect the succeeding streamer in a short time.

\section{Conclusions}

Creeping discharges from lightning impulse conditions over the surface of oil-immersed PE wire were studied under the influence of a grounded side electrode. Two methods of voltage application, one on the central line and the other on the binding wire, were used in this study. The results can be summarized as follows.

(1) Discharge forms were a tree-like structure for positive streamers and a bush-like structure for negative streamers. The propagation of negative streamers was significantly affected by a small groove on the surface of the wire insulator.

(2) The streamer length $\mathrm{Lm}$ increased linearly with the applied voltage $V_{m}$. At a fixed voltage, $L m$ of positive streamers was always greater than negative streamers. When the voltage was applied to the central line of the wire, $L m$ decreased with decreasing the distance $h$ between the test wire and the side electrode. Conversely, Lm increased when voltage was applied to the binding wire. In either case, $Q$ increased with decreasing $h$.

(3) A wire insulator puncture was caused by positive discharges and occurred just below the free end of the binding wire. The breakdown voltage dropped from 85 to $75 \mathrm{kV}$ when $\mathrm{h}$ was changed from 500 to $20 \mathrm{~mm}$.

(4) The streamer grew at a constant velocity of about $2.4 \mathrm{~km} / \mathrm{s}$ for positive streamers and about $1.8 \mathrm{~km} / \mathrm{s}$ for negative ones. The retarding of streamer propagation is due to the finite value of the potential drop inside the streamer channels $(7.5 \sim 9.5 \mathrm{kV}$ in this study).

(The authors wish to thank Y. Genba, T. Miyagawa and M. Kumazaki for their cooperation and assistance in our laboratory, and are indebted to Secom Foundation for their financial support of this research.)

(Manuscript received October 9, 1995, revised February 28, 1996)

\section{References}

[1] T. Shimazaki, "Flashover Characteristics and Surface Processes under Negative Impulse Voltage in Atmospheric Air", IEEE Trans. Elect. Ins., Vol. 27, No. 3, pp. 488-495, June 1992.

[2] H. Okubo, et al., "Creepage Discharge Propagation in Air and $\mathrm{SF}_{6}$ Gas Influenced by Surface Charge on Solid Dielectric", IEEE Trans. Dielectrics and Elect. Ins., Vol. 1, No. 2, pp. 294-304, April 1994.

[3] J. G. Anderson, et al., "The Propagation Mechanism of Impulse Creepage Discharges over Oil-Immersed Surfaces", AIEE, Trans. Part 1, Vol. 74, pp. 218-226, May 1955.

[4] R .J . Taylor, "Effect of Permittivity Matching on the Flashover of Solid/Liquid Interfaces", Proc. IEE, Vol. 124, No. 10, pp. 899-904, October 1977.

[5] J. C. Devins, et al., "Streamer Propagation in Liquids and Over Liquid-Solid Interfaces", IEEE Trans. Elect. Ins., Vol. EI-17, No. 6, pp.512-516, December 1982.

[6] P. Atten, et al., "Streamer Propagation over a LiquidSolid Interface", IEEE Trans. Elect. Ins. , Vol. 28, No. 2, pp. 230242, April 1993.

[7] A. Saker, et al., "Potential Distribution along Single Negative Creeping Streamer in Transformer Oil", IEE Proceedings-A, Vol. 140, No. 5, pp. 375-381, September 1993.

[8] T. Nishi, et al., "Impulse Creeping Discharge Characteristic in the Neighborhood of Insulator Supporting Point of Aerial Insulated Wires", Trans. I. E. E. J., Vol. 111, No. 2, pp. 49-59, 1991.

[9] E. F. Kelley, et al., "Measurement of Pre-breakdown Electric Fields in Liquid Insulants", Annual Report, CEIDP, pp.206212, 1978.

[10] R. Bartnikas, ENGINEERING DIELECTRICS Vol. III, AMTS Publication, 1994.

[11] M. Ishikawa, et al., "Pre-breakdown Density Change and Pre-breakdown Current in Transformer Oil", Trans. I. E. E. J., Vol. 102-A, No. 11, pp. 611-618, 1982, in Japanese.

[12] H. Kishida, et al., "The Discharge Figures in Insulating Oil and the Effect of a Slot on Surfac Discharge in Oil", Trans. I. E. E. J., Vol. 92-A, No. 5, pp. 246-250, 1972, in Japanese.

[13] H. Okubo, et al., "Creepage Discharge Propagation in Transformer Oil with Impulse Voltage", Int. Symp. on High Volt. Eng., paper 24-04, 1983.

[14] A. L. Wintenberg, et al., "Prebreakdown Current Pulses in n-Hexane and Other Dielectric Fluids", IEEE Trans. Elect. Ins., Vol. 24, No. 1, pp. 67-74, February 1989.

[15] E. F. Kelley, et al., "Simultaneous Measurement of Light Emission, Cument Pulses and Growth of Prebreakdown Streamers in Hexane", Annual Report, CEIDP, pp. 132-137, 1987. 
Ryoichi Hanaoka (Member) He was born on January

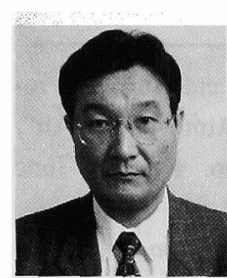
12,1950. He received the M.E. degree from Kanazawa University in 1981and the Ph.D. from Tokyo Institute of Technology in 1987 respectively in electrical engineering. Since 1996, he has been a Professor of electrical engineering at Kanazawa Institute of Technology and engaged in the studies of electrical conduction and breakdown in dielectric liquids and electric field calculation. He was a Visiting Scientist at MIT (MANSA) High Voltage Laboratory from 1993 to 1994 . He is a member of the Japan Society of Applied Physics and IEEE.

Toshiyuki Nishi (Member) He was born on March 8,

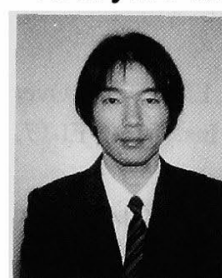
1959. He received the M.S. degree in electrical engineering from Kanazawa University in 1983 and joined USAC Engineering Co. Ltd.. In 1985, he joined Toyama National College of Technology as a research Associate and since 1993, he has been a Lecturer at Department of Electrical Engineering. He has been working on phenomena of creepage discharges in air and electric conduction in liquid dielectrics.
Toshiyuki Kohrin (Student member) He was born on

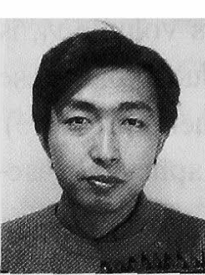
February 1, 1971. He received the M.S.degree in electrical engineering from Kanazawa Institute of Technology. Presently he is a doctoral student of Kanazawa Institute stitute of Technology at Department of Electrical Engineering. 